\title{
DEATH ANNOUNCEMENT IN PEDIATRIC POPULATION
}

\author{
F. BENNAOUI ${ }^{1,2}$,N. EL IDRISSI SLITINE ${ }^{1,2}$, F.M.R MAOULAININE ${ }^{1,2}$ \\ 1. Neonatal Intensive Care Department, Mohammed VI University Hospital \\ 2. Research Team for Childhood, Health and Development, Marrakech School of Medicine, Cadi Ayyad University, Marrakech.
}

\section{Introduction:}

-Doctors have to deal with illness, suffering and death.

-They must announce the death of a child to his family, which breaks the meaning of their life. This distress in others echoes ethical and moral suffering in the doctor.

\section{Materials \& Methods :}

-Transverse study carried out at the pediatric center of Mohamed VI University Hospital in Marrakech.

-Thirty four physicians (interns and residents) practicing at the pediatric center were included in our study.

\section{Results:}

-The doctors interviewed were with different levels of experience.

- The most dominant age group ranged between 20 and 30 years in $73.5 \%$. On average, doctors had announced the death between 5 to 10 times in $35.3 \%$ and between 10 to 20 times in $26.4 \%$ (Chart I) during their exercise.

-Twenty-five doctors had defined "death announcement" as a drama for the parents but also for them, six spoke of shock and three others of guilt.

- $5.8 \%$ of the cases were victims of aggression at the time of the announcement of death, Twenty-one doctors had felt the need for a support and a consultation with a psychologist to speak and express themselves.

-A percentage of $97 \%$ According to a doctor, they never received any training on the announcement of deaths and considered that training in this sense was useful and necessary (Graph II and III).

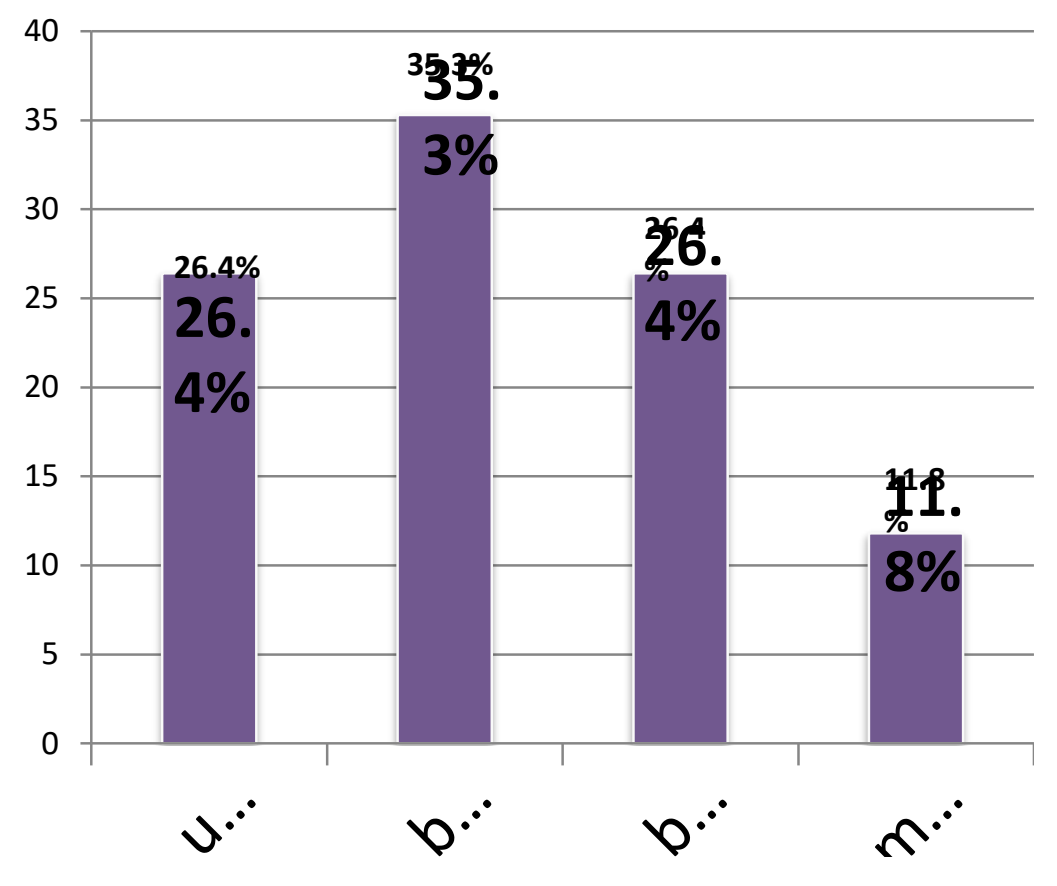

Chart I : number of time doctors announce death

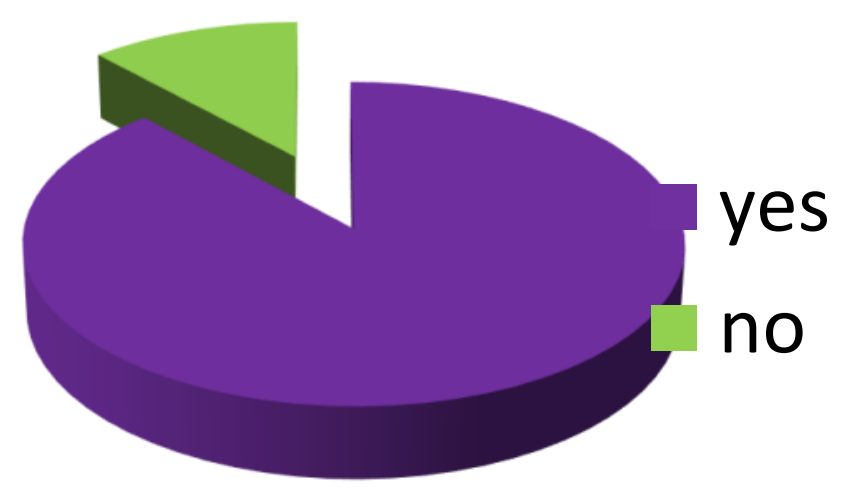

Chart II : number of doctor consider that training in this sense was useful and necessary

\section{Discussion:}

-The announcement of death can trigger stress, guilt, denial, anger, resignation, sadness for the caregiver. There can also be consequences of psychic trauma, distress, doubt, a feeling of helplessness.

-There is no way to announce a death that is not painful for families, but it is

-possible to put in place a rather stereotyped approach to avoid increasing the emotional trauma of everyone, including doctor. Not everyone has the caring and empathic detachment of being able to always assume, regardless of the circumstances, the announcement to relatives of a death.

-It is necessary to set up an authentic

-"Communication strategy" which with training allows to apply a true precept.

- The doctors emphasized that this dreaded moment could become a positive experience when it happened in a good therapeutic relationship. Some authors emphasize the importance of training physicians in the knowledge and management of their own defense mechanisms, given their influence on their practice and experience: projective identification, rationalization, trivialization,

-avoidance, false reassurance, derision, lie,

- flight forward, etc.

- The skills to acquire are theoretical (knowledge of defense mechanisms), practical (communication and listening) and human (reflections and sharing on death, suffering, their job).

\section{Conclusion:}

-The announcement of death is a difficult time technically and humanly for doctors.

-The need for theoretical, practical and human training on this point is important. Training must be early, repeated and continuous. 